\title{
A dança que nos escapa ${ }^{1}$ - o instante da presença
}

\author{
Mônica Medeiros Ribeiro \\ Departamento de Artes Cênicas \\ Universidade Federal de Minas Gerais, Brasil
}

DOI: https://doi.org/10.31492/2184-2043.RILP2020.38/pp.69-80

\begin{abstract}
Resumo
Este texto apresenta uma reflexão sobre o estado de presença experimentado pelo sujeito na improvisação em dança. Com o objetivo de pensar acerca da condição efêmera desse fazer artístico, por meio de uma revisão da literatura e da fruição de obras coreográficas, discute-se a dança como pensamento-sentimento do corpo e sua relação com a presença do sujeito no instante da improvisação inventiva.
\end{abstract}

Palavras-chave: Dança; improvisação; presença; instante.

\section{Abstract}

This text presents a reflection on the state of presence experienced by the subject in dance improvisation. With the objective of thinking about the ephemeral condition of this artistic doing, through a review of literature and the enjoyment of choreographic works, dance is discussed as a thought-feeling of the body and its relationship with the presence of the subject at the moment of inventive improvisation.

Keywords: Dance; improvisation; presence; moment.

\section{Introdução}

A transitoriedade marca nossa experiência no mundo fazendo com que o tempo, muitas vezes, seja traduzido como escasso. Talvez seja devido a essa escassez, que torna cada momento único e irrepetível, que valoremos de modo especial aquilo que nos aparenta prolongar o instante. O que é escasso torna-se, como consequência, desejado. $O$ tempo do instante precisa então ser vivido na sua máxima intensidade, porque ele se esvai.

A busca por prolongar cada instante, por aproveitar ao máximo a experiência, faz com que o exercício de estar no presente seja objetivo daqueles que desejam usufruir cada minuto de sua existência, ou daqueles que buscam enfrentar a antecipação ansiogênica que caracteriza muitos sujeitos na atualidade, ou ainda, do artista da cena que se empenha em viver plenamente o encontro com o público. Nas artes da cena, cuja natureza é efêmera, tem-se como prática fundamental o exercício de estar totalmente envolvido no aqui-agora da ação. O instante, pleno de presença, entretanto, não dura. Resta como memória naqueles que o viveram. Memória que se caracteriza por uma contínua atualização, movimento de invenção.

1. Este texto é o desenvolvimento da palestra A dança que nos escapa proferida no evento " $9+2$ Musas para um Museu”, promovido pelo Museu Mineiro e pelo Departamento de Filosofia da UFMG, em 2017. 
Desse modo, na dança, operamos entre o instante e a duração, entre a plenitude da presença no instante da ação e a mobilidade daquilo que fica na memória de quem a experimentou, seja dançando ou fruindo. A mitologia grega eterniza a dança quando nos oferece Terpsícore, sua musa. A que se deleita na dança, fruto da união entre Zeus e Mnemósine, Terpsícore é entidade inspiradora da criação artística e científica. Terpsícore nos lembra que a dança perdura, ainda que nos escape.

\section{Dança e leituras de mundo}

A dança abre espaço para construção de leituras de mundo. O pensamento sobre dança tem sido resultado de movimentos indisciplinares desse campo com a história, antropologia, filosofia, comunicação, psicanálise, ciências cognitivas. Praticante desse exercício, tenho discutido aspectos cognitivos, afetivos e inventivos da improvisação em dança contemporânea (Ribeiro, 2015; Ribeiro \& AGAR, 2011). Neste texto apresento uma reflexão acerca do estado de presença na improvisação em dança contemporânea, por meio de uma revisão da literatura somada à reflexão decorrente da experiência de fruição de dança. Mobilizada pela musa Terpsícore, penso a dança como deleite de nossa presença no mundo. Dança compreendida e vivida como prazer na experiência do movimento que adensa sentidos no corpo. Sigo o pensamento de Sheets-Johnstone quando diz que:

A dança é uma forma de arte criada, criada não para servir a qualquer propósito, mas criada por si própria. Sua integridade estética predomina sobre qualquer história que ela possa querer contar, por exemplo, ou qualquer "mensagem social”, que talvez queira apresentar. (Sheets-Johnstone, 2011, p.11).

A dança que abordaremos aqui diz respeito a uma proposição artística comprometida com a experimentação, a percepção, o auto-conhecimento, a transformação, a invenção e articulação estética de movimentos, quando os há. Desse modo, não busco compreender, nos exemplos citados ao longo deste texto, uma narrativa linear que a dança supostamente poderia representar. Não se trata de estudar a presença do sujeito em uma dança que conta histórias, o que não quer dizer que a dança não tenha um sentido em si. Ao contrário do que se possa pensar, a dança que não conta história pode ser ela mesma a corporificação de histórias do sujeito que a dança. Dança que corporifica memórias, estados do corpo, sentimentos, emoções, pensamentos.

É importante considerar que estudar a dança, como nos lembra Sheets-Johnstone, faz-nos atentarmo-nos para a cinestesia e sua relação com a percepção do mundo e ação no mundo, mostra-nos a potência cognitiva do corpo que elabora desenhos no espaço por via de variações de tônus muscular e deslocamentos. 
Esse estudo ainda nos leva a perceber a competência relacional da dança que promove encontros intersubjetivos para além da linguagem falada. Interesso-me neste momento pela reflexão sobre e a partir da dança contemporânea e da dança contemporânea improvisada, composta no instante da ação inventiva.

O que podemos saber do corpo pela dança? A dança corporifica pensamentos? Como me provoca a dança improvisada? O que penso sobre o mundo quando fruo improvisações em dança? Propor essas problematizações, mais que questões, não implica dizer que a dança é a representação de um sistema a ser decodificado. Podemos pensar, junto com Sheets-Johstone (1999), que, em termos de movimento, o sentido pode ser criado a partir da percepção e fruição de tendências, decisões, graus de força muscular, velocidades, expansões, recolhimentos resultantes do corpo em movimento. Aqui reforço que compreendo a dança como possibilidade de leitura do mundo. Mas importa dizer que trata-se aqui de uma leitura que não visa a compreensão imediata, mas sim uma leitura-invenção. Estou problematizando e, consequentemente, refletindo sobre e a partir do movimento dançado e não sobre o que significa determinado movimento, refletindo sobre dança a partir do que a dança me move. É importante ainda fazer a ressalva de que não pretendo responder essas questões, pois, aqui elas operam como mobilizadoras de práticas do pensar o mundo por meio da arte. Neste momento do existir no mundo, interessa-me a reflexão acerca da presença do sujeito que improvisa dançando.

\section{Conhecendo pela dança}

Até o início do século XX, a arte em geral teve que se esforçar para ser reconhecida como campo de conhecimento. A arte era vinculada apenas às emoções e a importância na construção de conhecimento era conferida ao pensamento, à mente, sendo a matéria corpo considerada imperfeita e relacionada às paixões, portanto não participante das ações cognoscitivas. Imaginar, apreciar, emocionar-se, sentir não eram associadas a atos cognitivos, mas sim a estados corporais compreendidos, pejorativamente, como subjetivos. Percebemos aí não somente a cisão entre mente e corpo como também entre razão e emoção. Como resquício de sintomas cartesianos provenientes da separação mente e corpo, a dança, arte do corpo, fora relacionada apenas ao entretenimento.

Entretanto, artistas pedagogos como Jaques Dalcroze (1921), compositor e pedagogo musical que priorizava o movimento corporal no ensino-aprendizagem de música, associou a aprendizagem de arte, no caso da música, ao exercício de processos corporais - como atenção, memória, tomada de decisão - inerentes ao ato cognitivo. Também John Dewey (2008), filósofo da educação, na década de 1930, propôs que a arte fosse compreendida como instância do fazer 
humano dedicada à construção de conhecimento do mundo. Ele considerava que a arte promovia a experiência consumatória, que, na sua integralidade, coadunava reflexão e emoção. Aproximadamente na metade do século XX despontaram autores/pesquisadores que reconheceram a arte como um tipo de conhecimento que demandava não apenas emoções e sentimentos, mas principalmente diversos aspectos cognitivos como se pode perceber pelos estudos de Lev Vygotsky, Elliot Eisner, Hower Gardner, Arthur Efland, entre outros. Considerar a dança como campo de conhecimento, premissa para a reflexão que aqui se apresenta, implica reiterar que mente e corpo são aspectos distintos da mesma matéria, que há dimensão mental na dança e corporal no pensamento. Com isso o ato de dançar pode ser estudado não somente por meio da investigação sobre sua condição sócio-histórica que permite que saibamos do mundo pela dança, como também pelos modos de articulação de movimentos ou não movimentos, pela observação atenta e afetiva dos estados do corpo em situação de dança. Observação essa que pode nos viabilizar a percepção e construção de subjetividades no e pelo movimento dançado. Além disso, com Antônio Damásio (1996), penso que é necessário considerar a forte imbricação existente entre razão e emoção, sendo ambos processos corporais presentes no ato de construção de todo conhecimento.

Assim, partimos de duas noções fundamentais. A primeira é a de que esta reflexão parte da ideia de uma dança que é poética construída de modo consciente pelo dançarino. Portanto, o acasalamento de um albatroz, por exemplo, não é uma articulação de movimentos dançados ${ }^{2}$, uma vez que lhe falta o ato de proposição artística. Trata-se, de fato, de uma sequência de movimentos executada com fins de atração para procriação. Nós podemos ver dança nessa sequência devido ao reconhecimento de procedimentos de repetição, sucessão, alternância e imitação como também da harmonia e coordenação dos movimentos. No entanto, todos esses procedimentos e características são pertencentes às experiências poéticas de quem vê e, de certo modo, atribui qualidades da intencionalidade artística humana aos movimentos dos albatrozes. Na dança de Ohad Naharin ${ }^{3}$, coreógrafo israelense, e dos dançarinos de Batsheva Dance Company (2001), para citar um exemplo, podemos perceber os mesmos procedimentos de composição. Entretanto esses estão articulados poeticamente com o fim de construir dança e possibilidade de fruição de dança. Dança-se para dançar, para dar a ver leituras de mundo, subjetividades tecidas pelo e no corpo em estado de arte.

A segunda noção refere-se às imbricações corpo-mente e razão-emoção, necessárias para se compreender a dança como campo do conhecimento humano,

2. Dança de acasalamento do albatroz https://www.youtube.com/watch?v=pFwxkyN9GSw

3. Naharin's Virus estreado em 2001 em Tel Aviv Trecho disponível em: https://www.youtube.com/watch? $\mathrm{v}=\mathrm{teMc} 2 \mathrm{cc} 6 \mathrm{~b} 6 \mathrm{M} \&$ list $=\mathrm{RD}$ teMc2cc6b6M\&t $=150$ 
como saber sentido (Hissa \& Ribeiro, 2017), referente a modos de articulação de movimentos e não-movimentos no tempo-espaço, decorrentes de relações intersubjetivas, de troca, diálogo dos dançarinos entre si, entre o dançarino e as coisas no mundo.

Podemos citar o espetáculo de dança A projetista $(2009)^{4}$, de Dudude Hermann, como uma dança-pensamento-corpo que coloca em questão o artista e sua sobrevivência. Ela não representa a sobrevivência, ela dança a sobrevivência do artista em meio à demanda burocrática das leis de fomento à cultura. Fazendo uso da palavra associada ao movimento, Dudude coloca em questão a condição do artista nos dias atuais. Entre variações de velocidade, impulsos e acentos nos movimentos, a dançarina se pergunta "Uma obra em dança serve para que? Para quem?" Devaneia com o gesto, permite-se perder na improvisação com os movimentos e palavras, encontrando logo a seguir o fio da meada. Nos momentos em que dança, seus movimentos não visam representar algo exterior a eles mesmos, mas sim portam sentido por advirem de um sujeito que se apresenta em determinadas circunstâncias. E a dançarina revela que sua dança é permeada pela pergunta "O que eu estou fazendo aqui?" e "O que você está fazendo aí?". Por meio de uma dança imbuída de reflexões, sua ação poética mostra o pensamento em movimento, ou movimento-pensamento, e seu desejo de estabelecer contato significativo com aquele que a vê.

Como nos diz Dudude, escrever, fazer dança é praticar sensibilidades 5 . Entretanto há que se ter em conta que a sensibilidade não se restringe ao aspecto afetivo, subjetivo. Advém da já aqui mencionada imbricação razão-emoção da qual decorre a presença cognitiva no sentir e vice-versa. Então se percebe-sente a sensação, e daí pratica-se sensibilidades ao incrementar esse sentir. Esse incremento pode dar-se, por exemplo, pela associação de movimentos articulados que ressaltam o fluxo da sensação. O encadeamento dos gestos/movimentos demandam ignições cognitivas que demonstram escolhas conscientes tanto no que se refere ao como quanto ao quando fazer determinado movimento, gesto, acento, pausa.

$\mathrm{Na}$ improvisação em dança aprimora-se o que Jaques-Dalcroze (1921) denominou de inteligência plástica que envolve a capacidade de mobilizar a atenção, a adaptação e a variação com intuito de cultivar a imginação. Essa experiência cognitivo-afetiva improvisacional pode ser significativa, como dizia John Dewey (2008), ao entretecer razão e emoção, teoria e prática, sujeito e mundo, constituindo-se uma experiência de participação e pertencimento.

4. A projetista estreado em 2009 em Belo Horizonte. Trecho disponível em: https://www.youtube.com/ watch? $=$ =tcQpM8tRYU8

5. http://www.dudude.com.br/dudude.html 
Assim, podemos dizer que a improvisação é qualificada por processos corporais de natureza cognitivo-afetiva. São eles: a simulação, a atualização e a adaptação/movimento de convergência (Ribeiro, 2015). A partir da simulação interna do movimento do outro (Gallese, 2010), dessa corporificação da alteridade, posso predizer "consequências" do movimento a ser realizado. Assim, o presente se amplifica estendendo-se ao passado e ao futuro, pois para predizer preciso conhecer - intimamente relacionado à memória - e ao predizer me lanço virtualmente a um futuro possível e provável. Nesse devir se estabelece a conexão eu-outro, imprescindível para a prática da improvisação. O processo de atualização implica a reorganização do próprio planejamento motor, estético, cognitivo-afetivo frente ao inesperado que vem do outro durante a improvisação. Para tanto faz-se necessário operar na aceitação, dizendo sim para o que vem a nós no jogo improvisacional. Já a adaptação é resultante do desejo de continuar no jogo improvisacional e se configura pela capacidade de agir em convergência, o que não exclui desacertos, oposições, falhas. Trata-se de experimentar o movimento em convergência, "que se refere ao estabelecimento de um consenso cognitivo-afetivo por meio de um acordo nem sempre passível de externalização por meio da linguagem verbal. Uma conversa que apenas se nota, mas que viabiliza a continuidade da exploração e criação conjunta" (Ribeiro, 2015, pp. 166-167). A convergência aqui proposta refere-se também a saber-se em estado de compartilhamento da experiência do movimento com o outro no presente ampliado.

Portanto, o saber que se constrói no improvisar é dependente do contexto e demanda flexibilidade cognitiva, que resulta do exercício consciente na experiência de atenção - que não necessariamente é a atenção focada -, da capacidade de adaptação, atualização e da promoção de variação de modo continuado nos entrecorpos presentes na improvisação. A dança, portanto, se constitui na relação e pela relação com o outro, existindo no entre (Hissa, 2017). Desse modo, não se estabiliza um aprendizado motor na improvisação em dança que garanta uma dança virtuosa. Não é como aprender a andar de bicicleta. Aprende-se a estar na improvisação, aprende-se a lidar com o acaso, o inesperado, a estar com o outro na experiência estética, partilhando espaço-tempo e subjetividades. Mais uma vez, vale citar a dançarina Dudude quando diz que na improvisação praticamos sensibilidades. 


\section{Espaço, tempo e peso entretecidos no corpo}

Como desenhar o espaço no invisível? (Dudude, online) ${ }^{6}$. Essa dança a qual nos referimos não dança no espaço, mas dança o espaço que se constrói ao passo da dança. Nada a priori, mas sim parte da experiência de dança. Pensamos assim que o espaço é corpóreo, e, o percebemos como consequência de nossos micro e macro-movimentos internos, externos. Na improvisação o espaço da ação vai aos poucos se configurando e proporcionando novas e provisórias organizações direcionais, e também de níveis e planos de movimento. No solo de Thomas McManus $^{7}$, coreografado pelo estadunidense William Forsythe, podemos notar a experiência das direções, planos e níveis que constroem uma noção de espacialidade flexível e inventiva. O espaço é desenhado pelo movimento do dançarino.

O mesmo pensamos sobre o tempo na dança. O tempo pode ser adensado, alargado, viabilizando sua experimentação no modo rápido, lento, lentíssimo, moderado. Na improvisação o corpo cria sua própria ritmicidade que dialoga com o jogo das tonicidades. Com isso a percepção temporal de quem frui a dança flexibiliza-se. Tempos outros. O tempo na dança nem sempre é o tempo métrico no qual se dança. Instaura-se uma temporalidade no dançar e essa pode ser percebida particularmente por cada espectador presente nesse acontecimento poético. Podemos, por exemplo, perceber o passar do tempo sendo desafiado pela marca da repetição percussiva presente no Bolero de Ravel $^{8}$, na hipnótica coreografia de Maurice Bejart, dançada por Sylvie Guillem. A cada organização de encadeamentos de gestos/movimentos desenham-se novas configurações espaço-temporais. Flexibiliza-se assim a percepção do espaço-tempo, sensibiliza-se o olhar daquele que observa um corpo que dança.

Quando Alain Badiou (1993), a partir de Nietzsche, diz que a dança é a metáfora do pensamento, lança a questão do peso como assunto fundamental nas reflexões sobre dança. Isso porque, a princípio, poderíamos associar o pensamento à mente $\mathrm{e}$, operando certo dualismo, subtrair o corpo, o peso da dança. Retirando o corpo estaríamos retirando o peso e nos restaria a leveza, que nos conduz à desejada abstração segundo Mallarmé. Como nos diz José Sasportes (1980, p.33) "A análise da dança feita por Mallarmé segue uma linha sempre mais abstrata, ocupando-se cada vez mais da escrita no espaço e cada vez menos do corpo que o percorre e define". Segundo esse autor, Mallarmé concebia a bailarina como a caligrafia de sua dança. Importava a dança e não o seu sujeito, dissociava-se a

6. https://www.youtube.com/watch?v=tcQpM8tRYU8

7. https://www.youtube.com/watch?v=iPScI15bUkE

8. Trecho do Bolero de Ravel, coreografado por Maurice Bejart. Disponível em: https://www.youtube.com/ watch? $\mathrm{v}=$ SS_WJmLGFrA 
bailarina da mulher ao dizer que o "corpo que dança é apenas um signo da dança" (Sasportes, 1980, p. 36). Dança sem peso, sem corpo.

Devemos, no entanto, considerar que Badiou refere-se ao pensamento como uma intensificação (a partir de Nietzsche) do próprio movimento e não a representação de algo a ele exterior. Para Badiou a dança é o movimento virtual, aquele que escapa da figura, do tempo, é pura intensidade. Nesse caso, se a dança é a intensificação do gesto apesar do sujeito desse gesto, podemos considerar a possibilidade de que se opere certo anonimato do corpo que dança. Subtrai-se o sujeito, restando a dança. Entretanto, a intensificação do movimento confere peso à dança fazendo com que Badiou perceba-a oscilante entre leveza e peso9 . A imagem da dança como leveza me diz de uma abordagem um tanto etérea da dança, aproximando-se de um pensamento desvinculado de um corpo que, necessariamente, lida com a gravidade. Mas, desde logo, podemos associar leveza a seu par peso e pensar num corpo que se modula em relação à força da gravidade. Marie Bardet acrescenta que Badiou trata o corpo dançante como um possível paradoxal que evidencia a relação complexa entre verticalidade e horizontalidade, entre leveza e peso. Segundo ela, a dança seria um lugar de partilha (Bardet, 2014). Interessa-me, a partir da ideia de partilha, perceber a improvisação em dança como experiência de relação, não somente entre leve e pesado, como também entre cima e baixo, direita e esquerda, frente e trás, coadunando espaço-peso, eu-outro, articulando subjetividades. Importa ainda ressaltar que a partilha aqui sugerida não se dá somente com harmonia, mas também com fricção, interrupção, pausa. Podemos notar essa dança que fricciona peso e leveza em Arrêtez, arrêtons, arrête $(1997)^{10}$, da coreógrafa francesa Matilde Monnier.

Jean-Luc Nancy (2008), talvez por sua proximidade a artistas como Matilde Monnier, tem em conta a importância do peso na dança. Ele refere-se à dança como experiência de gravidade, tensionando leveza e peso e inserindo a presentificaçao da dança no mundo, no real. A relação pesado/leve se complexifica na imbricação desses termos para dizer de uma dança que pensa o corpo ou que é mais que pensamento do corpo. Nancy vê o corpo dançante como corpo que pensa e pesa.

Nancy questiona ainda o fato da dança ter como objeto central o corpo e diz que o objeto da dança é a travessia do corpo, seu transe. Porque "os corpos estão

9. Quanto ao peso é fundamental retomarmos Rudolf Laban (1978) que o incluiu nos quatro fatores relativos ao movimento expressivo. Entre o fluxo, espaço, tempo, o peso é distinguido entre peso firme e peso leve. Assim, quando se fala de leveza, em termos da teoria do movimento na dança, estamos falando de peso, mais especificamente de um tipo de relação tônica que se estabelece com a atração da força de gravidade.

10. Trecho de Arrêtez, arrêtons, arrête (1997). Disponível em: https://www.youtube.com/ watch?v=fcDhQTIEo_U 
prestes a cair, à beira de um movimento, uma queda, uma lacuna, um deslocamento" (Nancy, 2008, p. 33) ${ }^{11}$. Então Bardet (2014) complementa sugerindo que a dança seja pensada a partir da dinâmica de movimentos, que implica pensar prioritariamente na relação que se estabelece entre a variação das intensidades, das transferências, jogos com o peso no espaço-tempo.

Quando Bardet (2014, p. 70, grifo da autora) nos diz "Pela caminhada, os pés dançando tecem com o solo as sensações com uma duração, corpos pe(n)sando sobre a Terra", ela corporifica o pensamento ao evidenciar a relação do movimento com o peso e do peso com o pensamento. Assim o pensamento é posto na condição de matéria que pesa.

A ideia da dança como metáfora do pensamento tem correlação com a proposta de Helena Katz (1994) da dança ser considerada pensamento do corpo. A partir dessa proposição, a teórica usa a expressão "pensamento do corpo" como metáfora do que acontece na construção do conhecimento artístico do corpo-mente-ambiente em dança. O pensamento, nesse contexto, não se relaciona a algum atributo "puramente mental", mas trata-se de metáfora que concretiza na linguagem verbal o que acontece no corpo que age de modo inteligente. Como propôs Sheets-Johnstone (1999), pensamento e movimento são aspectos de uma cinética corporal sintonizada com uma situação dinâmica. Podemos sugerir que se faz necessário incluir sentimentos nessa ideia dança. Lembrando que sentimento não significa somente a tristeza, alegria, raiva, mas também os chamados por Damásio (2010) de sentimentos corporais específicos ${ }^{12}$ - saberes do corpo; percepções de alterações que ocorrem no corpo; mapeamentos do corpo alterado pelas suas interações com o mundo e consigo próprio. Associar sentimentos ao pensamento do corpo é deixar ver que na dança, mesmo quando não se trabalha a partir de ou com emoções, operam-se equações sensíveis que implicam percepção, movimento e afecções. Dança como pensamento-sentimento do corpo.

\section{A dança e a presença que nos escapa}

Esse corpo que pensa sentindo sob a forma de dança ressalta espaços em trânsito, e a própria condição de transitoriedade do corpo. Espaços que se movem, deslizam, saltam, pausam. Desenhos espaciais construídos por corpos que são também espaços. Como nos diz Nancy (2008), os corpos levam seu espaço consigo quando se deslocam. A todo instante se forma e logo se vai uma figuração espacial específica. Tratam-se de configurações fugidias criando camadas de espacialidades instante após instante. No trânsito entre uma e outra espacialidade escapa-nos a possibilidade de estabelecimento de configurações estáveis.

11. Bodies is always about to leave, on the verge of a movement, a fall, a gap, a dislocation.

12. Os sentimentos corporais específicos são resultantes dos mapas proprioceptivos (Ribeiro, 2012, p. 76). 
Esse espaço que nos escapa é o próprio espaço para a existência, como diria Jean Luc Nancy. Espaços para a presença. A presença é aqui compreendida como uma possibilidade de consciência da continuidade espaço-tempo. Consciência e existência flexíveis, em um continuum de variações. Impossível então reter, capturar a presença. "Ou seja, a dança é imagem para o pensamento porque exige e faz uso da permanente transformação e criação, nela não há propriedades ou essência, mas a variabilidade e a afetação por uma cadeia infinita de conexões" (Testa, 2011, p.6). A composição no instante, característica da improvisação, tende a escapar do previsível indo em direção ao acaso, ao indeterminado.

A consciência do aqui-agora traz junto a si a percepção da própria existência e com isso queremos finalmente ressaltar a marca do sujeito que dança. Importa nomear o corpo que dança, por meio da corporificação de suas histórias, seus modos de existir. A nomeação a que nos referimos é aquela de reconhecimento do sujeito-corpo, de suas escolhas de movimento, de sua dança em relação ao mundo. Pois esta reflexão se faz a partir de danças autorais, que carregam marcas de singularidades. Interessa-nos a dança como presença de sujeito afetado pelo mundo. Isso torna premente a força da presença daquele que partilha espaço-tempo com o dançante, seja outro artista, seja o espectador que dança ao fruir a dança, escapando de uma suposta passividade. Todos sujeitos de corpos empáticos que ressoam o outro além de si próprio. Corpos em conexão.

Falar da dança de um corpo-sujeito no mundo em conexão é evidenciar o que Laurence Louppe (2012) chamou de geografia das relações. Podemos pensar a dança, a improvisação em dança, também como essas escritas de mundo sob a forma de relações entre os sujeitos-corpos em movimento. Relações essas que se estabelecem por meio de atenção e escolhas compartilhadas, transferências de peso, construindo uma poética das tonicidades. Tal poética, aqui tomada como própria do ato criador da composição artística, faz-nos ver a singularidade dos corpos que são os próprios criadores da experiência de composição no instante, de dança-improvisação. A composição entrelaça movimentos e modos de realizar e encadear movimentos. O modo singular de cada criador dançarino se faz perceptível pelo desenho das tonicidades, estados tônicos, do corpo, dos corpos em relação. A poética das tonicidades se presentifica com a presença daquele que frui a dança improvisação, que percebe, portanto, as relações, dinâmicas, fricções estabelecidas pelos sujeitos da dança. Não estou a falar aqui das organizações formais, se essas são compreendidas como apartadas do conteúdo e dos modos de existência, mas sim ressalto que a poética presentifica singularidades da subjetividade dos corpos dançantes. 
Corpos que se conectam por instantes, os quais em pouco tempo serão diluídos e novo contato se estabelecerá, seja como articulação entre movimentos seja como tangência entre os corpos que dançam. Essa impermanência em fluxo nos diz da potência do instante, no processo de comunicação na arte, de gerar sentido cinestésico que captura o olhar do espectador sem fixá-lo numa imagem recorrente. Esse olhar, que é mais que movimento, é percepção ativa, ação inventiva que confere espessura ao instante.

Seria a dança pura metamorfose, como dissera Paul Valery (Sasportes, 1980, p. 75)? Um jogo no qual o instante predomina sobre a duração restando ao espectador sua captura incessante? Ao sugerir que a dança é ato de metamorfose, Valery (2012) a equipara, como bem atentou Sasportes (1980), ao ato de pensar. Dança, pensamento, fluxo operam entretecidas aos sentimentos de todas essas trajetórias no espaço-tempo do corpo. A presença, no instante da improvisação - que se renova sucessivamente, faz dançar o espaço-tempo, e nos desafia a experimentarmos uma dança que nos escapa.

\section{Conclusão}

Pensar o mundo por meio do estudo reflexivo oriundo da fruição de danças aponta para a importância dos sujeitos de dança e suas poéticas próprias no âmbito das epistemologias do corpo nas artes da cena. Pesquisar o conhecimento nas artes do corpo, singularizado pelos saberes do corpo, é mais uma forma que nos possibilita reiterar a frágil condição de exclusividade da racionalidade nas operações cognoscitivas em arte. A imersão atenta em experiências afetivas de fruição e a prática do pensamento, do pensar-sentir, a partir do contato com a obra de dança, são vias a serem continuamente percorridas para que nos aproximemos dos conhecimentos/saberes construídos em estado de dança. Tensionados pela subjetividade que busca resistir a impressões, pensamentos, movimentos e sentimentos massificados, os improvisadores e os espectadores da dança mobilizam atenção e imaginação, entre outros tantos pontos da rede corporal engajada nessa experiência estética de relação, para construir espaços poéticos, redesenhar temporalidades e experimentar os possíveis daquilo que nos passa. Importa, assim, intensificarmos o exercício da presença na espessura do instante na improvisação em dança por meio da fruição atenta e afetiva de desenhos de corpos em trânsito, corpos em passagem. 


\section{Referências}

Badiou, A. (1993). Danse et penseé. Paris: Université Paris VIII.

Bardet, M. (2014). A filosofia da dança: encontro entre dança e filosofia. São Paulo: Martins Fontes.

Damásio, A. (1996). O Erro de Descartes - emoção, razão e o cérebro. São Paulo: Companhia das Letras.

Damásio, A. (2010). O livro da consciência: a construção do cérebro consciente. Portugal: Temas e Debates-Círculo de Leitores.

Dewey, J. (2008). El arte como experiencia. Barcelona, Espanha: Paidós estética 45. (Publicado originalmente em 1934).

Gallese, V. (2010). Mirror neurons and Art. Retrieved from: https://www.researchgate.net/ publication/284661288_Mirror_neurons_and_art

Hissa, C. E. V. (2017). Entre. In: Silva, M. I. S. \& Moreira, M. E. R. (Org.), Literatura: espaço fronteiriço. Colatina; Chicago: Clock Book.

Hissa, C. E. V. \& Ribeiro, M. M. (2017). Saber sentido. Conceição/Conception, 6(2), 90-109.

Jaques-Dalcroze. E. (1921). Rhythm, Music And Education. London: Chato \&Windus.

Katz, H. (1994). Um, Dois, três: a dança e o pensamento do corpo. (Tese Doutorado em Comunicação e Semiótica). PUC/SP, São Paulo.

Laban, R. (1978). Domínio do movimento. São Paulo: SUMMUS.

Louppe, L. (2012). Poética da dança contemporânea. Lisboa: Orfeu Negro.

Nancy, L. (2008). Corpus. New York: Fordham University Press.

Ribeiro, M. M. \& Agar, F. (2011). The empathy and the structuring sharing modes of movement sequences in the improvisation of contemporary dance. Research in Dance Education, v. 12, p. 71-85.

Ribeiro, M. M. (2012). Corpo, Afeto e Cognição na Rítmica Corporal de Ione de Medeiros: Entrelaçamento entre Ensino de Arte e Ciências Cognitivas. (Unpublished Tese de Doutorado em Artes). Escola de Belas Artes, Universidade Federal de Minas Gerais, Belo Horizonte.

Ribeiro, M. M. (2015). Experiencia de improvisação em dança. Pós, v.5, n.10, p.162-172.

Sasportes, J. (1980). Pensar a dança: a reflexão estética de Mallarmé a Cocteau. Lisboa: Coleção arte e artistas.

Scheets-Johnstone, M. (1999). The primacy of movement. Philadelphia, John Benjamins Publishing Company.

Sheets-Johnstone, M. (2011). Fenomenologia da Dança. Entrevista concedida a Monica Alarcón. Tradução de Charles Feitosa. O Percevejo, v.03, nº 02.

Testa, L. (2011). Que corpo é este que dança a imagem do pensamento? Alegrar, $\mathrm{n}^{\circ} 7$.

Valery, P. (2012). Degas dança desenho. São Paulo: Cosac Naify. (Publicado originalmente em 1938).

Data receção: $15 / 09 / 2019$

Data aprovação: 07/04/2020 